\title{
INVESTIGASI KANDUNGAN RADIOISOTOP DALAM SAMPEL AIR PADA SUNGAI DISEKITAR RUMAH SAKIT
}

\author{
Reza Achmad Furqoni ${ }^{1, *)}$ \\ ${ }^{1}$ Jurusan Fisika Universitas Negeri Semarang, Sekaran, Gunungpati, Kota Semarang, Indonesia 50229 \\ ${ }^{*}$ Email: rezaachmadfurqoni@gmail.com
}

\begin{abstract}
Abstrak
Dewasa ini pemanfaatan radioaktivitas semakin meluas, diantaranya dalam perkembangan ilmu kedokteran, bidang pertanian, bahkan penggunaan energi alternatif dari unsur radioaktif. Dalam bidang kedokteran misalnya, banyak rumah sakit yang telah memanfaatkan radioaktivitas sebagai salahsatu cara dalam menyembuhkan pasien. Hal ini tentu saja berimplikasi pada limbah yang dibuang oleh rumah sakit itu sendiri. Oleh karena itu, penelitian ini dilakukan untuk mengetahui besar interval cacah radiasi dan aktivitas jenis massa radioisotop serta kandungan unsur radioaktif dalam sampel air sungai disekitar rumah sakit. Penelitian dilakukan dengan mengobservasi lokasi penelitian, pengambilan sampel dan membawa sampel ke laboratorium untuk dianalisis. Diperoleh hasil kegiatan bahwa interval aktivitas massa jenis radioisotop dalam sampel air sungai 4,39 x10 ${ }^{-5} \mu \mathrm{Ci} / \mathrm{gram}-1,59$ $\mathrm{x} 10^{-4} \mu \mathrm{Ci} /$ gram. Tingkat kontaminasi radiosiotop lingkungannya adalah pada daerah kontaminasi tinggi untuk radiasi alpha $\left(\mathrm{C}>9,99 \times 10^{-5} \mu \mathrm{Ci} / \mathrm{gram}\right)$ dan kontaminasi sedang untuk radiasi beta $\left(9,99 \times 10^{-5} \mu \mathrm{Ci} /\right.$ gram $\geq \mathrm{C}<99,9 \times 10^{-5} \mu \mathrm{Ci} /$ gram $)$ berada di arah barat daya di rumah sakit. Daerah kontaminasi sedang untuk radiasi alpha $\left(0,99 \times 10^{-5} \mu \mathrm{Ci} / \mathrm{gram} \geq \mathrm{C}<9,99 \times 10^{-5} \mu \mathrm{Ci} / \mathrm{gram}\right)$ dan kontaminasi rendah untuk radiasi beta $\left(\mathrm{C}<9,99 \times 10^{-5} \mu \mathrm{Ci} / \mathrm{gram}\right)$ tersebar merata pada setiap lintasan dari lokasi penelitian.
\end{abstract}

Kata-kata kunci: Kandungan Radioisotop, Air Sungai, Rumah Sakit

\begin{abstract}
Nowadays radioactivity utilization is spread, for example in medicine field, agriculture, even used alternative energy from radioactivity element. In medine field, there are more hospitals that used radioactivity as one of way to healing people. This way absolutelly have implication to discarded waste from the hospital itself. Therefore, this research do for knowing radiation interval count dan activity of radioisotop mass then bring it to analyze in laboratory. The result is interval activity of radioisotop mass in sample of water $4,39 \times 10^{-5} \mu \mathrm{Ci} / \mathrm{gram}-1,59 \times 10^{-4} \mu \mathrm{Ci} /$ gram. Radioisotop contamination level is in high contamination area for alpha radiation $\left(\mathrm{C}>9,99 \mathrm{x} 10^{-5} \mu \mathrm{Ci} / \mathrm{gram}\right)$ and mid contamination area for beta $\left(9,99 \times 10^{-5} \mu \mathrm{Ci} /\right.$ gram $\geq \mathrm{C}<99,9 \times 10^{-5} \mu \mathrm{Ci} /$ gram $)$ in southwest from hospital. Mid contamination area for alpha radiation $\left(0,99 \times 10^{-5} \mu \mathrm{Ci} / \mathrm{gram} \geq \mathrm{C}<9,99 \times 10^{-5}\right.$ $\mu \mathrm{Ci} /$ gram $)$ and low contamination area for beta $\left(\mathrm{C}<9,99 \times 10^{-5} \mu \mathrm{Ci} / \mathrm{gram}\right)$ it spread out in every track of research location.
\end{abstract}

Keywords: Radioisotop Material, River Water, Hospital

\section{Pendahuluan}

Radioaktivitas merupakan suatu fenomena peluruhan unsur radioaktif yang disebabkan oleh inti suatu atom yang tidak stabil. Pada unsur radioaktif selalu terjadi proses peluruhan, karena unsur yang tidak stabil akan selalu berusaha untuk mencapai kestabilan, salah satunya dengan melepaskan energi yang berlebihan berupa radiasi (Bundjali, 2002). Dewasa ini pemanfaatan radioaktivitas semakin meluas, diantaranya dalam perkembangan ilmu kedokteran, bidang pertanian, bahkan penggunaan energi alternatif dari unsur radioaktif. Namun, selain pemanfaatan yang berguna bagi ilmu pengetahuan, unsur radioaktif juga dapat memberikan dampak negatif bagi kelangsungan hidup manusia atau alam, misalnya pencemaran lingkungan dan gangguan kesehatan. Selain itu, lamanya intensitas paparan radiasi unsur radioaktif juga akan sangat berdampak bagi yang terpapar, contohnya seseorang akan merasa pusing jika terpapar sinar gamma dalam waktu yang singkat, namun apabila terpapar lebih lama maka dapat menyebabkan iritasi kulit, mutasi gen bahkan kemandulan. Radiasi terbagi atas dua, yaitu radiasi buatan dan radiasi alam. Radiasi buatan merupakan radiasi nuklir yang dibuat dengan cara penembakan 
atau reaksi inti terhadap inti atom yang tidak radioaktif menjadi radioaktif, sedangkan radiasi alam yaitu radiasi yang berasal dari alam dan bukan buatan manusia. Radiasi alam juga terbagi atas dua, yaitu radiasi kosmik yang sumber radiasinya berasal dari luar bumi dan radiasi primodial yang sumber radiasinya berala dari kerak bumi. Radiasi alam pada lapisan kerak bumi yang berorde millyaran tahun dapat mempengaruhi kondisi lingkungan di atas permukaan bumi, seperti laut, gunung dan sungai (Yudhi, 2008).

Sungai merupakan sumber daya alam berupa jalur aliran air yang terbentuk secara alami dari proses geologi. Klasifikasi sungai berdasarkan arah aliran airnya dibedakan menjadi dua, yaitu sungai periodik yang aliran airnya hanya mengalir pada musim penghujan dan sungai episodik yang aliran airnya tetap. Secara geologi sungai mengalir dari hulu ke hilir, aliran sungai akan bermuara pada pantai atau laut (Ahira, 2011).

Sungai Lusi adalah salah satu sungai yang bermanfaat bagi masyarakat, khususnya bagi masyarakat sekitar aliran sungai. Salah satu manfaatnya adalah untuk irigasi dan untuk air bersih domestik. Ada dugaan bahwa air sungai Lusi terkontaminasi bahan radioisotop yang terbawa aliran air dari rumah sakit yang ada di dekat daerah aliran sungai. Dari pantauan citra, sungai Lusi merupakan pertemuan dari aliran beberapa anak sungai yang berfungsi sebagai tempat membuang limbah beberapa rumah sakit di daerah Purwodadi. Diduga bahwa limbah dari rumah sakit yang dibuang melalui anak sungai Lusi memiliki kandungan radioisotop dapat terbawa hingga ke sungai Lusi karena jarak yang dekat. Pada penelitian yang dilakukan oleh Hanifa pada daerah sekitar sungai Jati didapati bahwa kandungan radioisotop pada daerah tersebut adalah $2,7 \times 10^{-5} \mu \mathrm{Ci} /$ gram- $1,45 \times 10^{-4} \mu \mathrm{Ci} /$ gram, tergolong pada daerah dengan kontaminasi tinggi untuk radiasi alpha dan kontaminasi rendah untuk radiasi beta. Sungai Jati adalah anak sungai yang mengalir dari sebelah RSUD Soedjati Purwodadi bermuara di sungai Lusi. Dari dugaan di atas, maka ada kemungkinan air yang berasal dari sungai Lusi juga terkontaminasi bahan radioaktif yang berasal dari aliran sungai dari Jati dan rumah sakit. Untuk itulah perlu diteliti dan dibuktikan seberapa besar kandungan dan komposisi bahan radioisotop pada air sungai Lusi dan endapannya yang diduga tercemar limbah radioaktif rumah sakit. Radiasi nuklir yang dihasilkan oleh radioisotop alam akan dideteksi dengan menggunakan detektor Geiger Muller (GM).

\section{Metode Penelitian}

Langkah pertama yang dilakukan dalam penelitian ini adalah mengobservasi lokasi penelitian yakni di sekitar sungai Lusi tepatnya tempat pertemuan air sungai Jati yang diduga tercemar limbah radioisotop rumah sakit. Dalam proses survei ini akan diukur luas daerah yang diteliti dan kontaminasi dari sumber penentuan titik pengambilan sampel.

Teknik pengambilan sampel (air sungai dan endapan lumpur batuan) akan dilakukan secara sampling pada titik-titik yang akan ditentukan pada langkah pertama dan selanjutnya sampel dibawa ke laboratorium. Kemudian dilakukan analisis dan interpretasi data.

\section{Hasil dan Pembahasan}

\section{HASIL PENGUKURAN DI LAPANGAN}

Pengukuran di lapangan dimulai terlebih dahulu dengan melakukan survei, dan membuat lintasan serta menentukan titik ukur. Lintasan yang dibuat sebanyak 5 lintasan dengan masing-masing 15 titik ukur, jarak antar titik ukur ada 10 meter dan jarak tiap lintasan adalah 5 meter. Lokasi tidak digrid persegi karena tidak luas dan banyaknya gundukan pasir dan batu. Selanjutnya dilakukan pengukuran cacah lapangan dengan Radalert 50, dan diambil sampel tiap titik ukur, lalu dibawa ke laboratorium untuk dianalisis dan dicacah.

Tabel 1. Cacah radiasi di Lapangan (Lokasi Penelitian)

\begin{tabular}{|r|r|r|r|r|r|r|}
\hline \multirow{2}{*}{$\begin{array}{r}\text { Titik } \\
\text { Ukur }\end{array}$} & \multicolumn{6}{|c|}{ Cpm pada Lintasan } \\
\cline { 2 - 7 } & $\mathbf{1}$ & $\mathbf{2}$ & $\mathbf{3}$ & $\mathbf{4}$ & $\mathbf{5}$ & $\mathbf{6}$ \\
\hline $\mathbf{1}$ & 21 & 16 & 14 & 12 & 12 & 15 \\
\hline $\mathbf{2}$ & 14 & 19 & 14 & 20 & 24 & 22 \\
\hline $\mathbf{3}$ & 11 & 17 & 10 & 13 & 12 & 20 \\
\hline $\mathbf{4}$ & 8 & 20 & 24 & 18 & 19 & 17 \\
\hline $\mathbf{5}$ & 6 & 16 & 22 & 20 & 23 & 18 \\
\hline $\mathbf{6}$ & 15 & 12 & 27 & 15 & 24 & 19 \\
\hline $\mathbf{7}$ & 20 & 16 & 28 & 16 & 13 & 15 \\
\hline $\mathbf{8}$ & 11 & 14 & 18 & 17 & 12 & 19 \\
\hline $\mathbf{9}$ & 15 & 10 & 13 & 17 & 18 & 24 \\
\hline $\mathbf{1 0}$ & 12 & 15 & 28 & 30 & 18 & 36 \\
\hline $\mathbf{1 1}$ & 13 & 21 & 18 & 23 & 12 & 22 \\
\hline $\mathbf{1 2}$ & 14 & 10 & 13 & 4 & 19 & 9 \\
\hline $\mathbf{1 3}$ & 12 & 17 & 11 & 13 & 12 & 10 \\
\hline $\mathbf{1 4}$ & 15 & 9 & 7 & 12 & 19 & 14 \\
\hline $\mathbf{1 5}$ & 12 & 15 & 7 & 16 & 16 & 18 \\
\hline
\end{tabular}

\section{HASIL PENGUKURAN DI LABORATORIUM}

Setelah diukur cacah radiasi di lapangan dilakukan pengambilan sampel sesuai dengan titik ukur pencacahan di lapangan lalu dibawa ke laboratorium untuk dilakukan pengolahan sampel. Sampel awalnya dibungkus dengan allumunium foil agar tidak terkontaminasi lalu sampel dikeringkan lalu dihaluskan dengan menggunakan mortal, kemudian 
sampel dibakar dengan suhu mencapai $800^{\circ} \mathrm{C}$, sampel yang sudah halus kemudian dicampur aquades dan dikeringkan dengan maksud menghilangkan pengotor yang ada pada sampel, setelah itu sampel debu dicacah dengan Radalert 50.. Cacah radiasi sampel air sungai dan endapannya tercantum dalam Tabel 2 dan Tabel 3 .

Tabel 2. Cacah radiasi sampel air laut dan endapannya di Laboratorium.

\begin{tabular}{|r|r|r|r|r|r|r|}
\hline \multirow{2}{*}{$\begin{array}{r}\text { Titik } \\
\text { Ukur }\end{array}$} & \multicolumn{6}{|c|}{ Cpm pada Lintasan } \\
\cline { 2 - 7 } $\mathbf{1}$ & 14 & 17 & 14 & 14 & 18 & 9 \\
\hline $\mathbf{2}$ & 10 & 16 & 15 & 13 & 17 & 14 \\
\hline $\mathbf{3}$ & 17 & 16 & 18 & 11 & 14 & 13 \\
\hline $\mathbf{4}$ & 8 & 11 & 15 & 14 & 17 & 22 \\
\hline $\mathbf{5}$ & 9 & 12 & 12 & 17 & 12 & 19 \\
\hline $\mathbf{6}$ & 13 & 8 & 9 & 11 & 18 & 15 \\
\hline $\mathbf{7}$ & 10 & 13 & 15 & 22 & 18 & 11 \\
\hline $\mathbf{8}$ & 18 & 13 & 13 & 26 & 20 & 20 \\
\hline $\mathbf{9}$ & 10 & 14 & 13 & 14 & 14 & 9 \\
\hline $\mathbf{1 0}$ & 13 & 10 & 18 & 27 & 15 & 12 \\
\hline $\mathbf{1 1}$ & 17 & 20 & 21 & 12 & 16 & 19 \\
\hline $\mathbf{1 2}$ & 10 & 14 & 12 & 13 & 16 & 9 \\
\hline $\mathbf{1 3}$ & 20 & 15 & 10 & 16 & 13 & 16 \\
\hline $\mathbf{1 4}$ & 10 & 11 & 16 & 20 & 15 & 13 \\
\hline $\mathbf{1 5}$ & 27 & 19 & 17 & 29 & 16 & 17 \\
\hline
\end{tabular}

Sampel yang dicacah bermassa 10 gram dan dicatat data cacah laboratorium lalu diolah dengan menggunakan Ms. Excel didapat hasil aktivitas jenis massa radioisotop seperti pada Tabel 3.

Tabel 3. Aktivitas jenis massa radioisotop $(C)$ dalam sampel.

\begin{tabular}{|r|r|r|r|r|r|r|}
\hline \multirow{2}{*}{$\begin{array}{r}\text { Titik } \\
\text { ukur }\end{array}$} & \multicolumn{6}{|c|}{ C tiap Lintasan $\left(\boldsymbol{C} \mathbf{1 0}^{-\mathbf{5}} \boldsymbol{\mu c i} / \boldsymbol{g r a m}\right)$} \\
\cline { 2 - 7 } $\mathbf{1}$ & $\mathbf{2}$ & $\mathbf{3}$ & $\mathbf{4}$ & $\mathbf{5}$ & $\mathbf{6}$ \\
\hline $\mathbf{1}$ & 7,69 & 9,33 & 7,96 & 7,69 & 9,88 & 4,94 \\
\hline $\mathbf{2}$ & 5,49 & 8,78 & 8,23 & 7,14 & 9,33 & 7,69 \\
\hline $\mathbf{3}$ & 9,33 & 8,78 & 9,88 & 6,04 & 7,69 & 7,14 \\
\hline $\mathbf{4}$ & 4,39 & 6,04 & 8,23 & 7,69 & 9,33 & 12,08 \\
\hline $\mathbf{5}$ & 4,94 & 6,59 & 6,59 & 9,33 & 6,59 & 10,43 \\
\hline $\mathbf{6}$ & 7,14 & 4,39 & 4,94 & 6,04 & 9,88 & 8,23 \\
\hline $\mathbf{7}$ & 5,49 & 7,14 & 8,23 & 12,08 & 9,88 & 6,04 \\
\hline $\mathbf{8}$ & 9,88 & 7,14 & 7,14 & 14,28 & 10,98 & 10,98 \\
\hline $\mathbf{9}$ & 5,49 & 7,69 & 7,14 & 7,69 & 7,69 & 4,94 \\
\hline $\mathbf{1 0}$ & 7,14 & 5,49 & 9,88 & 14,83 & 8,23 & 6,59 \\
\hline $\mathbf{1 1}$ & 9,33 & 10,9 & 11,53 & 6,59 & 8,78 & 10,43 \\
\hline $\mathbf{1 2}$ & 5,49 & 7,69 & 6,59 & 7,14 & 8,78 & 4,94 \\
\hline
\end{tabular}

\begin{tabular}{|r|r|r|r|r|r|r|}
$\mathbf{1 3}$ & 10,9 & 8,23 & 5,49 & 8,78 & 7,14 & 8,78 \\
\hline $\mathbf{1 4}$ & 5,49 & 6,04 & 8,78 & 10,98 & 8,23 & 7,14 \\
\hline $\mathbf{1 5}$ & 14,8 & 10,4 & 9,33 & 15,93 & 8,79 & 9,33 \\
\hline
\end{tabular}

Berdasarkan Tabel 1 dan Tabel 2 diatas, telah dilakukan analisis data dalam bentuk kurva 2D cacah per menit versus jarak ukur untuk semua lintasan.

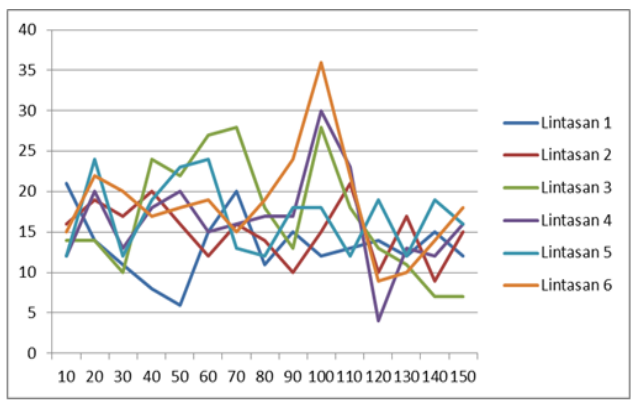
jarak ukur

Gambar 1. Grafik Cacah Lapangan versus

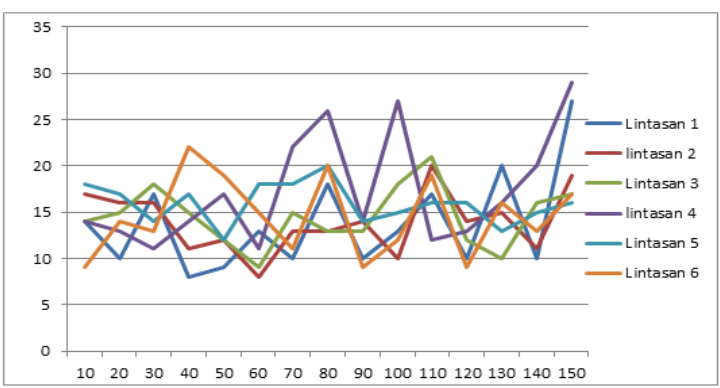

Gambar 2. Grafik Cacah Laboratorium versus jarak ukur

Dari Gambar 1 dan Gambar 2 dapat diketahui jelas bahwa kedua kurva ini berbeda dan menunjukan bahwa ada perbedaan antara cacah lapangan dan cacah laboratorium. Untuk lintasan 1 sampai 6 pada jarak ukur 10-50 meter kurva hampir sama pada range 9-22 cpm, pada jarak ukur 90-110 meter dapat dilihat bahwa grafik cacah laboratorium terendah sedangkan cacah lapangan tinggi dan pada jarak ukur akhir menunjukan cacah laboratorium tinggi dan cacah lapangan rendah.

Pada lintasan 1 (titik ukur 1 , titik ukur 7), lintasan 2 (titik ukur 4), lintasan 3 (titik ukur 6, titik ukur 7), lintasan 4 (titik ukur 2), lintasan 5 (titik ukur 5, titik ukur 6), dan lintasan 6 (titik ukur 1, titik ukur 2, titik ukur 3 dan titik ukur 9), dapat diketahui bahwa cacah per menit yang terukur di lapangan dan di laboratorium memiliki selisih yang cukup besar (diatas $5 \mathrm{cpm}$ ) dimana cacah di lapangan lebih besar dibanding dengan cacah di laboratorium, hal ini menunjukan bahwa pada saat cacah di lapangan terindikasi adanya gas yang ada di sekitar lokasi titik ukur sehingga saat alat pendeteksi Radiolert-50 didekatkan dengan titik ukur maka gas di sekitar titik ukur atau yang ada di titik ukur menyebabkan cacah radiasi besar, seperti yang sudah diketahui bahwa partikel alfa sangat mudah berinteraksi dengan udara 
dan terjadi ionisasi setelah beberapa saat terpancar. Sedangkan pada lintasan 1 (titik ukur 3, titik ukur 8, titik ukur13, titik ukur 15), lintasan 3 (titik ukur 3, titik ukur 14, titik ukur 15), lintasan 4 (titik ukur 7 , titik ukur 8 , titik ukur 12, titik ukur15) dan lintasan 5(titik ukur 1, titik ukur 8), dapat diketahui bahwa cacah di lapangan jauh lebih kecil dibanding cacah di laboratorium (selisih lebih dari $5 \mathrm{cpm}$ ). Hal ini menunjukan bahwa sampel terbungkus atau tertutup oleh pengotor atau materi lain, sehingga ketika sampel dianalisis di laboratorium hingga tahap pembersihan atau pemisahan dari pengotor dengan aquades baru didapat sampel yang baik dan ketika dicacah menunjukan besar cpm yang lebih besar dibanding cacah di lapangan.

Untuk titik ukur yang lain dengan selisih kurang dari $5 \mathrm{cpm}$ menunjukkan bahwa sampel tersebut hampir sesuai antara cacah di lapangan maupun cacah di laboratorium namun tetap saja terkandung pengotor ataupun gas yang ada disekitar titik ukur namun dengan jumlah relatif kecil.

\section{INTERVAL AKTIVITAS JENIS}

Berdasarkan analisis di laboratorium dan perhitungan, maka didapat interval aktivitas jenis massa radioisotop sebesar $4,39 \times 10^{-5} \mu \mathrm{Ci} /$ gram $-1,59$ $\mathrm{x} 10^{-4} \mu \mathrm{Ci} /$ gram. Aktivitas terendah terdapat pada lintasan 1 (titik ukur 4) dan lintasan 2 (titik ukur 6), sedangkan untuk aktivitas tertinggi pada lintasan 4 (titik ukur 15). Aktivitas jenis massa radioisotop tiap lintasan ditunjukan pada Tabel 3.

Pada lintasan 1 aktivitas tinggi pada titik ukur 13 yaitu $1,09 \times 10^{-4} \mu \mathrm{Ci} /$ gram dan titik ukur 15 yaitu $1,48 \times 10^{-4} \mu \mathrm{Ci} /$ gram, untuk aktivitas rendah pada titik ukur 4 dengan $4,39 \times 10^{-5} \mu \mathrm{Ci} /$ gram. Untuk lintasan 2 aktivitas tinggi pada titik ukur 11 yaitu $1,09 \times 10^{-4} \mu \mathrm{Ci} /$ gram dan di titik ukur 15 yaitu $1,04 \times 10^{-4} \mu \mathrm{Ci} /$ gram, sedangkan untuk titik ukur 6 adalah aktivitas terendah dengan $4,539 \times 10^{-5} \mu \mathrm{Ci} /$ gram. Lintasan 3 pada titik ukur 11 yaitu $1,15 \times 10^{-4} \mu \mathrm{Ci} /$ gram merupakan aktivitas tertinggi dan titik ukur 6 dengan $4,94 \times 10^{-5} \mu \mathrm{Ci} /$ gram adalah aktivitas terendah. Untuk lintasan 4 aktivitas tinggi pada beberapa titik ukur yaitu titik ukur 7, titik ukur 8 , titik ukur 10 , titik ukur 14 dan titik ukur 15 dengan $1,20 \times 10^{-4} \mu \mathrm{Ci} /$ gram, $1,42 \times 10^{-4} \mu \mathrm{Ci} /$ gram, $1,48 \times 10^{-4} \mu \mathrm{Ci} /$ gram, $1,09 \times 10^{-4} \mu \mathrm{Ci} /$ gram dan 1,59 $\mathrm{x} 10^{-4} \mu \mathrm{Ci} /$ gram, sedangkan aktivitas terendah pada titik ukut 3 dan 6 dengan $6,04 \times 10^{-5} \mu \mathrm{Ci} /$ gram. Untuk lintasan 5-titik ukur 8 adalah aktivitas tertinggi dengan $1,09 \times 10^{-4} \mu \mathrm{Ci} /$ gram dan aktivitas terendah pada titik ukur 5 dengan $6,59 \times 10^{-5} \mu \mathrm{Ci} /$ gram. Aktivitas tinggi pada lintasan 6 terdapat pada titik ukur 4 , titik ukur 5 , titik ukur 8 dan titik ukur 11 yaitu $1,20 \times 10^{-4} \mu \mathrm{Ci} /$ gram, $1,04 \times 10^{-4} \mu \mathrm{Ci} /$ gram,

$1,09 \times 10^{-4} \mu \mathrm{Ci}$ /gram dan $1,04 \times 10^{-4} \mu \mathrm{Ci} /$ gram, dan titik ukur 1, titik ukur 9, titik ukur 12 adalah titik ukur dengan aktivitas terendah yaitu $4,94 \times 10^{-4} \mu \mathrm{Ci} / \mathrm{gram}$. Pada titik ukur lain sepanjang lintasan 1 sampai lintasan 6, aktivitas jenis massa radioisotop yang sedang tersebar merata.

\section{KONTAMINASI RADIOISOTOP LINGKUNGAN}

Analisis sampel dilaboratorium menunjukkan bahwa aktivitas jenis massa radioisotop dalam sampel berkisar antara 4,39 $\times 10^{-5} \mu \mathrm{Ci} /$ gram $1,59 \times 10^{-4} \mu \mathrm{Ci} /$ gram.

Daerah kontaminasi terbagi atas 3 (Wardhana, 1994), maka diketahui bahwa lintasan 1 (titik ukur 13, titik ukur 15), lintasan 2 (titik ukur 11, titik ukur 15), lintasan 3 (titik ukur 11), lintasan 4 (titik ukur 7 , titik ukur 8 , titik ukur 10 , titik ukur 14 dan titik ukur 15), lintasan 5 (titik ukur 8), lintasan 6 (titik ukur 4, titik ukur 5, titik ukur 8, titik ukur 11) merupakan daerah dengan tingkat kontaminasi tinggi untuk radiasi alpha $\left(\mathrm{C}>9,99 \mathrm{x} 10^{-5} \mu \mathrm{Ci} /\right.$ gram $)$ dan kontaminasi sedang untuk radiasi beta $(9,99 \mathrm{x}$ $10^{-5} \mu \mathrm{Ci} /$ gram $\geq \mathrm{C}<99,9 \mathrm{x} \quad 10^{-5} \mu \mathrm{Ci} /$ gram $)$. Sedangkan titik ukur lain yang ada sepanjang lintasan 1 sampai lintasan 6 tergolong daerah kontaminasi sedang untuk radiasi alpha $\left(0,99 \times 10^{-5} \mu \mathrm{Ci} / \mathrm{gram} \geq \mathrm{C}\right.$ $<9,99 \times 10^{-5} \mu \mathrm{Ci} /$ gram) dan daerah kontaminasi rendah untuk radiasi beta $\left(\mathrm{C}<9,99 \times 10^{-5}\right.$ $\mu \mathrm{Ci} /$ gram).

\section{Simpulan}

1) Interval aktivitas jenis massa radioisotop dalam sampel air sungai adalah 4,39 $\mathrm{x} 10^{-5} \mu \mathrm{Ci} /$ gram $-1,59 \times 10^{-4} \mu \mathrm{Ci} /$ gram .

2) Tingkat kontaminasi radiosiotop lingkungan di daerah aliran sungai Lusi adalah

a. Daerah kontaminasi tinggi untuk radiasi alpha $\left(\mathrm{C}>9,99 \times 10^{-5} \mu \mathrm{Ci} /\right.$ gram $)$ dan kontaminasi sedang untuk radiasi beta $\left(9,99 \mathrm{x} \quad 10^{-5} \mu \mathrm{Ci} /\right.$ gram $\geq \mathrm{C}<99,9 \mathrm{x}$ $10^{-5} \mu \mathrm{Ci} /$ gram) berada di arah barat daya di rumah sakit.

b. Daerah kontaminasi sedang untuk radiasi alpha $\left(0,99 \times 10^{-5} \mu \mathrm{Ci} /\right.$ gram $\geq \mathrm{C}$ $<\quad 9,99 \times \quad 10^{-5} \quad \mu \mathrm{Ci}$ /gram) dan kontaminasi rendah untuk radiasi beta $\left(\mathrm{C}<9,99 \times 10^{-5} \mu \mathrm{Ci} /\right.$ gram $)$ tersebar merata pada setiap lintasan dan lokasi penelitian.

\section{Ucapan Terimakasih}

Terimakasih kepada Tuhan Yang Maha Kuasa karena telah memberi kemudahan dalam menyelesaikan penelitian ini. Kepada istri tercinta, keluarga besar Tegal dan Panunggalan yang telah memberikan motivasi bekerja, dan seluruh pengurus Laboratorium Fisika Universitas Negeri Semarang 


\section{Daftar Acuan}

[1] Achmad, H. 2001. Kimia Unsur dan Radiolimia. Edisi kedua, PT. Citra Adytia Bakti, Bandung.

[2] Adhirga, Y. 2013. Analisis Dampak Perubahan Curah Hujan, Luas Tambak Garam, dan Jumlah Petani Garam Terhadap Produksi Usaha Garam Rakyat di Kecamatan Juwana Kabupaten Pati. Universitas Diponogoro, Semarang

[3] Akhadi, M. 2000. Dasar-Dasar Proteksi Radiasi. Rhineka Cipta, Jakarta.

[4] Bundjali, B. 2002. Kimia Inti. Penerbit ITB, Bandung.

[5] Dlouhy, Z. 1994. International Basic Safety Standars for Protection Against ionising Radiation. Safety series No. 115-1, AEA Vienne Austria.

[6] Elbaradei, M. 2004. Remediation of Areas Contaminated by Past Activities and Accidents. Safety Standaerds Series no. WS-R, IAEA Vienna Austria.

[7] Pasangka, B. 2008. Kajian Kandungan Radioisotop dan Unsur Lain Dalam Deposit Mineral Serta Kontaminasinya Pada Lingkungan di Timor Barat NTT. Universitas Gajah Mada, Yogyakarta.

[8] PP Nomor. 35 Tahun 1991 tentang Sungai.

[9] Telford, W.M. Geldart, L.P. Sheriff, R.E. Keis, D.D. 1976. Applied Geophysics. Cambridge University Press, New York.

[10] Wardhana, W. A. 1994. Teknik Analisis Radioaktivitas Lingkungan. Andi Efset : Yogyakarta 
